\title{
CONCEPTUAL DESIGN OF A TOOL SUPPORTING THE "LAST MILE" LOGISTICS IN HOSPITALS
}

\author{
Davide Aloini $^{\mathrm{a}, 1}$, Elisabetta Benevento ${ }^{\mathrm{b}}$ and Alessandro Stefanini ${ }^{\mathrm{a}}$ \\ ${ }^{a}$ University of Pisa, Italy \\ ${ }^{b}$ University of Rome Tor Vergata, Italy
}

\begin{abstract}
This work reports preliminary outcomes from the LINFA project, which aims to develop a technological, information and organizational system for improving the procurement process of medicines and medical devices within healthcare organizations. Accordingly, the paper presents insights from a real case study within an Italian Hospital where the project team has gone through-out the phases of process discovery, modelling and use-cases identification and analysis to devise an integrated tool for supporting logistic decisions and operations. Findings provide readers with a complete identification and formalization of the conceptual requirements of such tool for supporting pharmaceutical last-mile logistic within a hospital.
\end{abstract}

\section{KEYWORDS}

Healthcare, Pharmaceutical Logistics, Last-mile, Hospital Information System, LINFA Project

\section{INTRODUCTION}

Logistics function has gained a strategic role in the management of hospitals. As a matter of fact, hospital material management has been identified as one key cost driver to cope with steadily increasing healthcare costs in industrialized countries (Volland et al., 2017). This is particularly true for pharmaceutical logistics where supply chain management has become more and more complex in the last decades since it has to meet life-saving interests at sustainable costs. Solving this trade-off requires to enable the collaboration of different stakeholders such as pharmaceutical manufacturers, wholesalers, distributors, customers, information service providers and regulatory agencies.

'Last-mile' of logistics in this context refers to the challenge of the final movements of goods and services to the delivery or consumption point. The 'last-mile' of pharmaceutical goods tends to be less efficient and most problem-prone. One side this is due to the variability and unpredictability of the patient profile and the high demand for care (Wieser, 2011; Bourlakis et al., 2011), on the other to the high process fragmentation and the increasing touch-points that are often related to additional costs and complications. Nevertheless, emerging IT tools (such as Radio Frequency Identification, Enterprise Resource Planning), vertical organizations as well as the new disruptive technologies for last-mile logistics solutions (e.g., drones, automatic guided vehicles) have risen consistent expectations of reducing the costs of distribution while guaranteeing adequate service levels. In such an evolving context, scholars and practitioners widely agree that hospitals must pay close attention to the inventory and information technology system used to manage their daily operations (Kritchanchai et al., 2017). As a matter of fact, technological progress and Information flows management are a prominent source of improvement of the hospital practices (Mazzocato et al., 2010). Definitely, they can enable communication and process coordination supporting the information sharing between the partner institutions (laboratory, blood transfusion center, etc.). Internal and external integration is therefore the new challenge for hospitals (Krichanchai and MacCarthy, 2017).

${ }^{1}$ Corresponding author - davide.aloini@unipi.it 
This work aims to report a practical experience from the LINFA project which objective is to develop a technological, information and organizational system for improving the procurement process of medicines and medical devices within health care organizations. The system is developed through models of forecast analysis and process optimization, advanced logistics practices, increased traceability with the use of RFID technologies and health and administrative data flows. Accordingly, the paper presents a real case study within an Italian Hospital where the project team has gone through-out the phases of process discovery, use-cases identification and analysis to devise an integrated tool for supporting logistic operation (Niranjan et al., 2012; Govindan, 2013). Results provide readers with a complete identification and formalization of the conceptual requirements of such tool for supporting pharmaceutical last-mile logistic within a hospital or hospital network setting.

\section{THE LINFA PROJECT AND RELATED OBJECTIVES}

LINFA is a research project funded by the Region Tuscany and carried out jointly by companies and research organizations with a focus on the regional drug logistics at the hospital level. The idea originating the project is to provide decision support tools to facilitate the task of operators, who deal with the replenishment orders and inventory management in hospital departments, while developing methodologies, practices and cooperation tools oriented to their extension and scale up.

Exploiting the availability of historical information about drugs and patients, the development of forecasting methods, together with optimization algorithms integrated in a shared technological platform, the project aims to deliver a technological, information and organizational system for improving the procurement process of medicines and medical devices within healthcare organizations. In so doing, it will make possible to move towards the minimization of stocks and the effective and efficient management of medicines, with a consequent reduction in healthcare expenditure.

Specifically, the LINFA system aims to integrate models for demand forecast and process optimization systems with advanced logistics practices, increased traceability with the use of RFID technologies by exploiting health and administrative data flows. To this purpose, LINFA would make available and shares information about departmental stocks, hospital stocks and the actual availability of drugs at regional central warehouses. LINFA also proposes an innovative approach for managing safety stocks by enabling a unitary virtual warehouse based on the real stocks stored in the several hospital departments and permitting the transfer of drugs between them.

Summarizing, LINFA aims to provide a tool:

- To monitor the current drugs stock and support medical staff in the re-ordering process;

- To keep under control the expiring date of drugs;

- To support more efficient reorders thanks to the demand forecasting and optimization algorithms;

- To share stock information among the different hospital departments to deal with emergency orders;

- To record drugs withdrawals and exchanges between different departments.

\section{METHOD}

To discover and formalize functional requirements for the LINFA System and to fully understand the hospital staff needs, we accomplished a case study within an Italian Hospital. It goes through the following three phases:

1. Analysis of the drug management process: This phase aimed at understanding the current procedures of drugs procurement and inventory management and identifying potential criticalities and bottlenecks within the process. The analysis was carried out within an Italian Hospital by means of field observations and interviews with hospital staff. The resulting process model was represented through the BPMN language- see Chinosi \& Trombetta (2012) for methodological details about this notation - and validated with hospital staff.

2. Primary users' and functional requirements identification: The aim of this phase was to identify the stakeholders of LINFA system users and to collect key information from their field experience. Identifying who will be involved in the information gathering process is important due to the input these 
individuals can provide regarding technological needs. The collection of functional requirements was conducted through interviews and focus groups with hospital staff. In so doing, we focused on two main questions: (i) How can the LINFA system contribute to the operational goal of each user? (ii) What features are desirable for achieving such result? The outcome of this step was a set of functional requirements written in natural language.

3. Formalization of functional requirements for the LINFA system: In this step, we formalized the functional requirements previously identified, by using the UML (Unified Modelling language) language (Rumbaugh et al., 2017). In so doing, it was possible to automated traceability of requirements in the subsequent phases of LINFA system development. Specifically, we translated conceptual requirements into UML use case diagrams representing the relationships between primary users and system functionalities. Each use case was accompanied by text explaining the purpose of the use case as well as what functionality is accomplished when it is executed. The use cases can capture the intended behavior of the system being developed without specifying how the behavior is implemented.

\section{RESULTS}

\subsection{Analysis of the Drug Management Process}

The drug management process includes the following sub-phases: inventory management, drug procurement, drug receipt and storage, and control and reporting (reported in fig 1). Each sub-phase is detailed below.

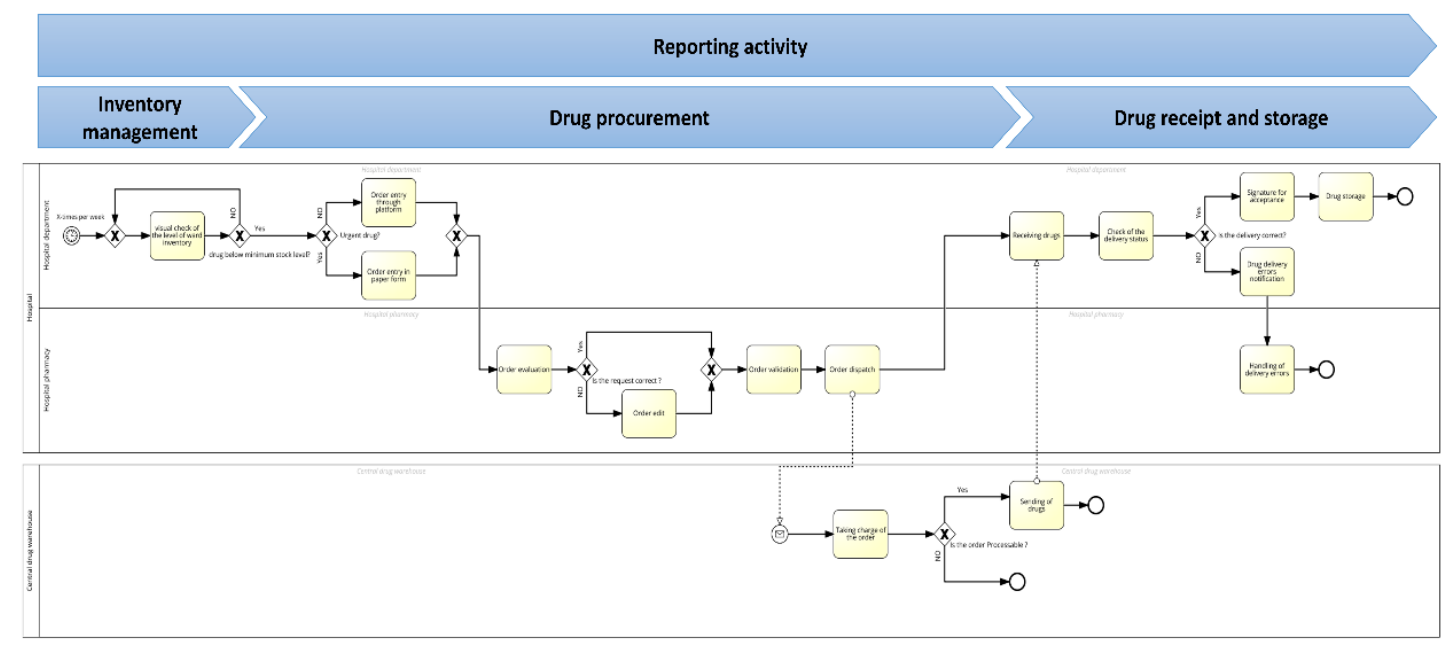

Figure 1. Drug Management process: a BPMN Diagram

- Inventory Management: At fixed intervals and independently by prescription, the head nurse or nurses check the ward inventory level, manage drug's expiration dates, and quantify the drug needs. Such monitoring is usually carried out by a visual check. In addition, the evaluation of the quantity of drugs to be reordered is based on nurse personal experience;

- $\quad$ Drug procurement: Regular requests for drugs are executed by the head nurse through a specific IS platform. On the other hand, urgent drug requests are drawn up in paper form. Each type of request is validated by the hospital pharmacy and sent to a central drug warehouse;

- Drug receipt and storage: Once drugs arrive in the ward, the head nurse checks the delivery status and signs for acceptance on the bill of delivery. Specifically, each delivery is checked against the relevant purchase order and each container physically verified. The storage of drug packages on the appropriate shelves is handled by nurses and nursing assistants. The order criteria may vary from ward to ward. In the case of incomplete or incorrect delivery, the pharmacy has to define a new replenishment request;

- Control and Reporting: The hospital pharmacy periodically monitors and measures the performance of hospital departments as concerning the drugs management. 
Interview with participants have shown that the drug management process suffers from several criticalities. The lack of control over actual consumptions, together with the unpredictability of the demand for healthcare services, causes high levels of ward inventory and, then, considerable holding costs, obsolescence risk, and a negative effect on the hospital service level. In addition, drug replenishment requests are usually independently from real needs and quantities are determined based on nurse personal experience. This often results in oversized and too frequent orders. Drugs are often stocked without a standard codification and may be placed in different positions, thus determining an inefficient space utilization and code retrieval. Consequently, applying First-In-First-Out (FIFO) picking rule is also difficult. Accordingly, nurses and nursing assistants tends to be overly involved in logistics duties, reducing the time available for medical activities.

\subsection{Primary Users' and Functional Requirements Identification}

Primary users within the hospital who will be using the LINFA system include: Hospital pharmacy, Doctor, Head nurse, and Nurse. We defined a set of 17 functional requirements according to the aforementioned primary users. For sake of brevity, table 1 shows just an excerpt of such list.

Table 1. An Excerpt of the Functional Requirements List

\begin{tabular}{l|l}
\hline \multicolumn{1}{c|}{$\begin{array}{c}\text { Functional } \\
\text { requirement }\end{array}$} & \multicolumn{1}{c}{ Description } \\
\hline $\begin{array}{l}\text { Drug stocks } \\
\text { visualization }\end{array}$ & $\begin{array}{l}\text { The system must provide real-time information about the quantity and type of drugs in } \\
\text { stock, keeping track of the batch number and the expiration date. }\end{array}$ \\
\hline Drug stocks update & $\begin{array}{l}\text { The system must allow the updating of the drugs in stock, as a result of drug loading } \\
\text { (storage of drugs) and unloading (administration to patients). }\end{array}$ \\
\hline $\begin{array}{l}\text { Notification of new } \\
\text { availability of a drug }\end{array}$ & $\begin{array}{l}\text { The system must notify the unavailability of the requested drug and the failure to process } \\
\text { the order, indicating a potential date for drug availability. }\end{array}$ \\
\hline
\end{tabular}

\subsection{Formalization of Functional Requirements for the LINFA System}

The overall use case diagram including all functional requirements identified in the previous step is shown in figure 2. Some use cases, such as drug stocks update and order status display, incorporate the behavior of other use cases as fragments of their own behavior. On the other hand, others (e.g., order edit) are an incremental extension to a base use case (e.g., order validation and dispatch). Each use case was also translated into structured textual specification format to identify the temporal sequence of behaviors and the state of the system and of the actors before and after the execution of that use case. As an example, the textual specification of the use case "Notification of urgent drug availability" (Table 2) is given below.

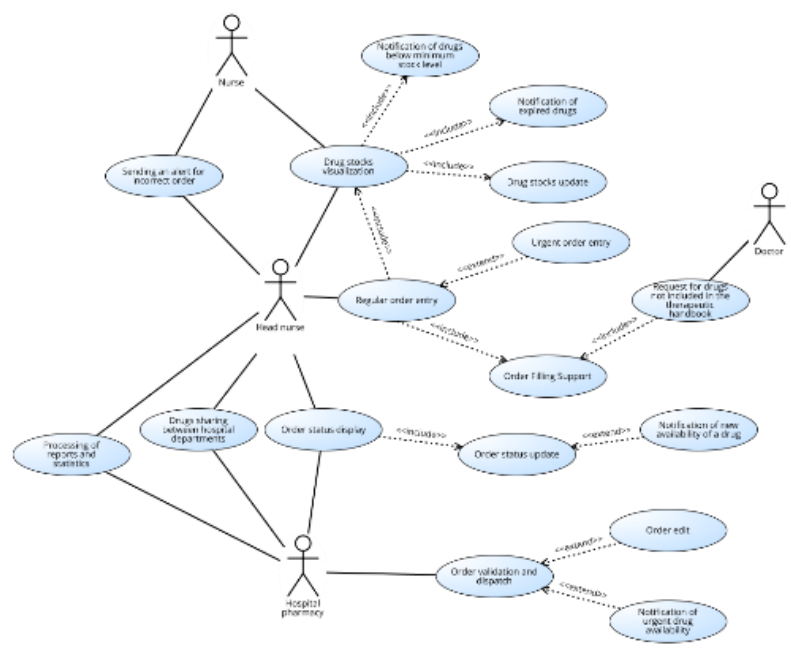

Figure 2. Overall Use Case Diagram 
Table 2. Textual Specification of the Use Case "Notification of Urgent Drug Availability"

\begin{tabular}{|l|l|}
\hline Use case name & Notification of urgent drug availability \\
\hline Actor & Hospital Pharmacy \\
\hline Pre-conditions & The operator must be logged into the system. The system must have notified an urgent order \\
\hline $\begin{array}{l}\text { Basic flow of } \\
\text { events }\end{array}$ & $\begin{array}{l}\text { 1) The operator displays order items; } \\
\text { 2) The operator selects the drug code and enters it in the search field; } \\
\text { 3) The system shows the list of the wards where the drug is available with the related quantity; }\end{array}$ \\
\hline Extensions & $\begin{array}{l}\text { 2.a The system is not able to find any correspondence with the parameters entered; } \\
\text { 2.a.1. The operator checks the text correctness in the search field. }\end{array}$ \\
& $\begin{array}{l}\text { 3.a The system shows a null result for the search } \\
\text { 3.a.1 The system shows the appropriate message and terminates the operation. }\end{array}$ \\
\hline Post-conditions & The system shows the list of hospital departments with drug availability \\
\hline
\end{tabular}

\section{CONCLUSION}

This work reports some preliminary outcomes from the LINFA project. Final expected benefits from the project include:

- reduction of errors and delivery times for drugs reorders;

- reduction of expiring drugs in hospital departments;

- improvement of the overall procurement and cost awareness at every level of the supply chain;

- support to monitoring and quick identification of anomalous situations;

- optimization of transit points from the central warehouse to the hospital departments;

- reduction of drugs stock costs and needed space in hospital departments.

Future project steps will concern the design and test of demand forecasting and optimization algorithm, conceptual architecture design, design of the interfaces, development of a test version, field testing.

\section{ACKNOWLEDGEMENT}

This work has been partially supported by LINFA (Logistica INtelligente del FArmaco) project, funded by Regione Toscana under the call PAR FAS 2007-2013, LINEA D’AZIONE 1.1 - BANDO FAR FAS 2014

\section{REFERENCES}

Bourlakis, M., F. Clear, and L. Patten. 2011. "Understanding the UK Hospital Supply Chain in an Era of Patient Choice." Journal of Marketing Management 27 (3-4): 401-423. doi:10.1080/0267257X.2011.547084.

Chinosi, M., \& Trombetta, A. (2012). BPMN: An introduction to the standard. Computer Standards, 34(1), 124-134.

Govindan, K. (2013). Vendor-managed inventory: a review based on dimensions. International Journal of Production Research, 51(13), 3808-3835.

Krichanchai, S., \& MacCarthy, B. L. (2017). The adoption of vendor managed inventory for hospital pharmaceutical supply. The International Journal of Logistics Management, 28(3), 755-780.

Kritchanchai, D. \& Hoeur, S. \& Engelseth, P. (2017). Develop a strategy for improving healthcare logistics performance. Supply Chain Forum: An International Journal. 19. 1-15.

Mazzocato et al., 2010 Mazzocato, P., C. Savage, M. Brommels, H. Aronsson, and J. Thor. 2010. "Lean Thinking in Healthcare: A Realist Review of the Literature." Quality and Safety in Health Care 19 (5): 376-382.

Niranjan, T. T., Wagner, S. M., \& Nguyen, S. M. (2012). Prerequisites to vendor-managed inventory. International Journal of Production Research, 50(4), 939-951.

Rumbaugh, J., Booch, G., \& Jacobson, I. (2017). The unified modeling language reference manual. Addison Wesley.

Volland, J., A. Fügener, J. Schoenfelder, and J. O. Brunner. 2017. "Material Logistics in Hospitals: A Literature Review." Omega 69: 82-101.

Wieser, P. 2011. "From Health Logistics to Health Supply Chain Management." Supply Chain Forum: An International Journal 12 (1): 4-13. 